\title{
A ambiguidade como princípio retórico em Shakespeare - Muito Banulho por Nada (c. 1598) e Otelo (c. 1604): estudos de caso ${ }^{1}$
}

\author{
Ambiguity as a rhetorical principle in Shakespeare - Much Ado \\ about Nothing (c. 1598) and Othello (c. 1604): case studies
}

Ricardo Cardoso

Universidade de São Paulo (USP)

DOI: https://doi.org/10.5902/2176148556900

Resumo: A conhecida ambiguidade atribuída aos textos de Shakespeare tem sido tema de exames. Este artigo investiga determinada explicação para o fenômeno creditada a alguns estudiosos da História do Pensamento Político Moderno. Segundo propõem, a polifonia em certas obras decorreria do uso pelo dramaturgo da técnica retórica in utramque partem, abordagem de dois lados opostos de um mesmo tópico, na dramatização de questões políticas delicadas. Utilizaremos como estudos de caso duas peças escritas em contexto de intensas discussões sobre guerra e paz em Londres, buscando compreender como Shakespeare representou o assunto por meio de perspectivas antagônicas.

Palavras-chave: Shakespeare. Ambiguidade. Retórica. Espanha.

Abstract: The ambiguity ascribed to Shakespeare was a recent subject of academic scrutiny. This article investigates the history of modern political thought scholarship for that phenomenon. According to this proposition, polyphony would derive from the use of the rhetorical technique known as in utramque partem, an approach of two opposite sides of the same topic, in order to stage delicate political questions. Using a pair of plays written in the context of intense discussions about war and peace in London as case studies, I seek to explore how Shakespeare represented the Anglo-Spanish conflict through antagonistic perspectives.

Keywords: Shakespeare. Ambiguity. Rhetoric. Spain.

1 Agradeço à Fundação de Apoio à Pesquisa do Estado de São Paulo pelo fundamental apoio financeiro à minha pesquisa de Doutorado (FAPESP, processo 2017|0745-4) e estágio no Shakespeare Institute sob supervisão do professor Martin Wiggins (FAPESP, processo 2019|01297-3), do qual nasceu este artigo. 
Nos últimos anos, tem despertado interesse entre estudiosos do drama renascentista inglês e do pensamento político moderno a ambiguidade com que Shakespeare (1564-1616) parece ter retratado situações e temas contemporâneos. A apresentação de diferentes pontos de vista de uma mesma questão em suas peças torna difícil depreender a opinião do dramaturgo sobre os assuntos que abordava. Como afirma o historiador David Armitage, Shakespeare seria em si mesmo um bom sinônimo de "elusivo", se isso é "resultado de uma evasão deliberada, é mais difícil de dizer" $(2009 \text {, p. } 25)^{2}$. Para Stephen Greenblatt, principal nome do Ricardo movimento crítico conhecido como Novo Historicismo, essa obliquidaCardoso de evidente nas obras seria resultado de sua formação em uma família católica que testemunhara eventos traumáticos durante a Reforma Protestante (2012, p. 150-175). O filho de Mary Arden e de John Shakespeare teria herdado o medo de ser descoberto e perseguido pelo credo dos pais, a evasão seria, então, fruto do treino para ocultação de qualquer dado que pudesse revelar as suas crenças, o que sentia e o que pensava ${ }^{3}$.

A suposição de Greenblatt é hoje de difícil verificação, senão impossível. Por outro lado, podemos dizer que, tecnicamente, pode não estar muito longe da verdade. $\mathrm{O}$ uso de dissimulação no comportamento social mostrava-se fundamental para a sobrevivência de católicos em alguns reinos reformados, como a Inglaterra ${ }^{4}$. Nos anos 1590, foi recrudescida nos domínios de Elizabeth I (1533-1603) a perseguição a sacerdotes e praticantes da velha fé. Em 1595, o jesuíta Robert Southwell (1561-1595) foi condenado por, dentre outros delitos, ter ensinado a mulher que o escondia a responder às autoridades que o buscavam em sua casa com frases de duplo sentido, assim não estaria cometendo o pecado da mentira e ao mesmo tempo evitaria a prisão de seu protegido. Comovido com o julgamento e morte de Southwell, e provavelmente em resposta a eles, outro jesuíta, padre Henry Garnet (1555-1606), escreveria um tratado

2 "Whether this elusiveness was the result of deliberate evasiveness is more difficult to tell: [...]", Armitage (2009, p. 25).

3 É importante lembrarmos aqui que o pioneiro estudioso da História Social da Arte, Arnold Hauser, afirmava em meados do século passado que a instabilidade trazida pela Reforma Protestante e outros eventos que chacoalharam a Europa, como a descoberta do Novo Mundo, teria sido a propulsora de ambiguidades e contradições nas obras artísticas e tratados políticos produzidos entre a década de 1510 e início do século XVII, período que ele atribui ao estilo chamado de maneirismo (HAUSER, 2007). 4 "A dissimulação religiosa entre cristãos, o chamado nicodemismo, era corrente na Europa no começo da modernidade, quando católicos na Inglaterra e protestantes na Itália foram obrigados a desenvolver estratégias de sobrevivência que geraram divisões similares entre a afirmação pública e a crença privada". Schwartz (2009, p. 100). 
em que desenvolveria melhor a prática ensinada por aquele, o Tratado da Equivocação (c. 1595). A obra circulou em manuscrito, e alguns anos mais tarde contribuiria para a condenação do autor, capturado e executado logo após envolvimento involuntário na Conspiração da Pólvora em $1605^{5}$. Em seu texto, Garnet ensina detalhadamente a composição de sentenças que teriam dois sentidos, úteis em inquéritos pelas autoridades da Coroa: um deles seria aparente e incorreto, o outro, oculto e verdadeiro ${ }^{6}$. Shakespeare parece ter entrado em contato com essa prática e com o texto. Curiosamente, Southwell era seu parente pelo lado materno, e a teorização de equivocação por Garnet é citada por Brabantio em Otelo (c. 1604) $(1.3,214-5)$ e pelo personagem do porteiro em Macbeth (c. 1606) $(2.2,6-9)^{7}$. O efeito de dubiedade nas peças de Shakespeare se daria, segundo outra corrente de estudos, por conta da aplicação de técnicas retóricas, sobretudo o in utramque partem - abordagem de dois lados de uma mesma questão - prática comum em exercícios da educação humanista nas escolas de gramática inglesas, frequentadas na infância e adolescência pelos dramaturgos. A ideia central desses exercícios era a de que a defesa de um lado deveria encontrar um equivalente simétrico na defesa do lado oposto ${ }^{8}$. 0 crítico Joel B.

5 Antonia Fraser (2000) faz um rico relato sobre o processo que levou à Conspiração da Pólvora e à condenação de Garnet.

6 O nome original é Treatise of Equivocation. A expressão poderia ser traduzida como Tratado da Ambiguidade, entretanto, talvez "equivocação" seja um termo mais adequado por abranger tanto o sentido de "ambiguidade" como o de uma espécie de auto-engano sobre a legitimidade do que é dito, mesmo que essa ocorresse em apenas uma das interpretações possíveis. Como afirma o Oxfod English Dictionary, equivocation na época de Shakespeare significava "the use of words or expressions that are susceptible of a double signification, with a view to mislead; esp. [especially] the expression of a virtual falsehood in the form of a proposition which (in order to satisfy the speaker's conscience) is verbally true". Simpson; Weiner (1989, Volume V, p. 360).

7 Para as datas de composição das peças, utilizo aquelas propostas por Martin Wiggins (WIGGINS, 2007-atual). Para a numeração das linhas, utilizo The New Oxford Shakespeare (2017).

8 Aristóteles em Arte Retórica alude à prática in utramque partem: "Pois o discurso científico é próprio do ensino, e o ensino é aqui impossível, visto ser necessário que as provas por persuasão e os raciocínios se formem de argumentos comuns, como já tivemos a ocasião de dizer nos Tópicos a propósito da comunicação com as multidões. Além disso, é preciso ser capaz de argumentar persuasivamente sobre coisas contrárias, como também acontece nos silogismos; não para fazer uma e outra coisa - pois não se deve persuadir o que é imoral - mas para que não nos escape o real estado da questão e para que, sempre que alguém argumentar contra a justiça, nós próprios estejamos habilitados a refutar os seus argumentos. Ora, nenhuma das outras artes obtém conclusões sobre contrários por meio de silogismos a não ser a dialética e a retórica, pois ambas se ocupam justamente dos contrários." Aristóteles (2012, p. 10). Cicero considerava de extrema importância o exercício da abordagem in utramque partem no estudo de uma causa forense: "102 No que me diz respeito, costumo esforçarme para que cada um me informe, ele próprio, a respeito de seu caso, e para que ninguém mais esteja presente, a fim de que fale à vontade; costumo também defender a causa do adversário, de modo que ele defenda a sua e exponha abertamente o que refletiu a respeito de seu caso; assim, quando ele se vai, assumo sozinho, com total imparcialidade, três papéis: o meu, o do adversário e o do juiz. Se o tópico é de tal sorte que traga mais ajuda do que prejuízo, julgo que devo utilizá-lo em meu discurso; quando me deparo com mais desvantagem do que vantagem, rejeito-o e abandono completamente". Scatolin (2009, p. 213-4). Agradeço ao historiador André Sekkel Cerqueira pelas ricas sugestões para melhor compreensão dessa técnica na retórica clássica. 
Altman aprofundou, em 1978, o estudo do in utramque partem como elemento de construção para ambiguidades discursivas no que ele chama de The Tudor Play of Mind, expressão que considerou sintetizar a estrutura retórica dos textos dramáticos do período, especialmente de autores como Christopher Marlowe (1564-1593) e Thomas Kyd (1558-1594). Em 2006, Jean E. Howard publicou o artigo "Dramatic Traditions and Shakespeare's Political Thought" na primeira coletânea de textos investigativos sobre o pensamento político moderno de especificidade britânica, British Political Thought in History, Literature and Theory: 1500-1800, organizada por David Armitage, em que ela retoma a Ricardo metodologia de análise desenvolvida por Altman, mas dessa vez aplicando-a Cardoso unicamente à obra de Shakespeare 9 .

Desde então, é crescente a atenção dada ao poeta por estudiosos do pensamento político moderno, sobretudo aqueles associados à chamada Escola de Cambridge, o que impulsionou em 2009 a publicação do primeiro volume de textos que utilizam a obra do dramaturgo como fonte para essa área de estudos, co-organizado também por David Armitage ${ }^{10}$. No volume, historiadores e críticos exploram a forma como o poeta teria utilizado o in utramque partem nas tramas, por exemplo através da oposição entre dois personagens, cada um representando um lado do problema em foco ${ }^{11}$.

Dado que ambivalências não eram incomuns nas obras e nos textos produzidos na passagem do século XVI para o XVII, e que o uso do in utramque partem auxiliava em sua geração no drama, como sugerem Altman e os estudiosos do pensamento político moderno, nos interessa entender como se dá a aplicação desse recurso retórico por Shakespeare na abordagem de questões políticas delicadas em momentos conturbados. $O$ assunto desperta atenção quando, ao pesquisar o impacto da Guerra Anglo-Espanhola (1585-1604) na obra do autor, descobrimos surpreendentes contradições na representação do inimigo no palco ${ }^{12}$. Os casos

9 Joel B. Altman retomará o estudo do utramque partem em 2010, dedicando-o exclusivamente à Otelo. É possível que ele tenha retornado à sua metodologia justamente pelo resgate dessa por Jean E. Howard, visto que o artigo dessa influenciou os estudos sobre o pensamento político em Shakespeare a partir da publicação em 2006.

10 Desde os anos 1960, um grupo de historiadores da Universidade de Cambridge notabilizou-se no estudo do pensamento político moderno pela busca do sentido que conceitos políticos possuíam em cada época em que foram utilizados. O grupo passou a ser conhecido a partir de então como "Escola de Cambridge", e seu movimento metodológico como "Contextualismo Linguístico".

11 Quentin Skinner em texto conclusivo analisa a convergência dos estudos do utramque partem na obra de Shakespeare publicados na coletânea. Skinner (2009, pp. 271-281).

12 A reverberação desse impactante evento militar no drama do período foi o objeto de estudo de meu Mestrado (CARDOSO, 2016) e de um artigo preliminar que resume algumas das questões tratadas naquele momento, publicado em livro organizado por Régis A. B. Closel e Ronaldo Marin (CARDOSO, 
mais flagrantes aparecem em Muito Barulho por Nada (c. 1598) e Otelo (c. 1604), pois em ambas as obras há um par de personagens antagônicos com ressonâncias ibéricas. Na primeira, temos a Monarquia Hispânica representada por um lado pelo simpático Dom Pedro, príncipe de Aragão, e por outro, pelo vilão Dom João, meio irmão daquele ${ }^{13}$. Na segunda peça, o velho oponente da Inglaterra é retratado na dupla protagonista/ antagonista. Como Dom Pedro de Aragão, Otelo representa a Espanha heroica em suas campanhas militares - ambos surgem em cena como líderes de exércitos vencedores. Iago, como Dom João, apresenta o aspecto traiçoeiro e dissimulado creditado à mesma Monarquia. Dado que tanto em Muito Barulho por Nada quanto em Otelo temos a dramatização simultânea de "duas Espanhas", podemos tomar a ocorrência e o contexto histórico imediato em que surgiram como estudos de caso. Tentaremos entender

A ambiguidade como princípio retórico em Shakespeare

Um dado comum às duas peças e que deve ser levado em conta é a composição em momentos de intensa discussão sobre a continuidade da Guerra Anglo-Espanhola. Há consenso de que Muito Barulho por Nada foi escrita em 1598, ano em que, depois de uma década de angústia coletiva, iniciada com o envio da Invencível Armada (1588) por Felipe II (1527-1598) para destituir do trono a rainha inglesa, houve a primeira possibilidade diplomática de paz entre os dois reinos ${ }^{14}$. 0 monarca francês Henri IV (1553-1610), costumeiro aliado militar de Elizabeth, buscou naquele ano encerrar seu próprio conflito com a Espanha e insistiu para que a Inglaterra fosse incluída nas negociações. A rainha mostrou-se favorável ao diálogo intermediado pelo Arquiduque Alberto de Áustria (1559-1621), então governador dos Países Baixos espanhóis. Essa oportunidade de encerramento do longevo embate gerou discus-

2015). Agradeço o importante apoio dado durante o Mestrado pela FAPESP no Brasil (FAPESP, processo 2013/24175-4) e no Shakespeare Institute em 2015 (FAPESP, processo 2015/05657-3).

13 Em fins do século XVI, o termo "Monarquia Hispânica" era utilizado para designar o ramo ibérico da dinastia Habsburgo que governava diversos territórios no continente europeu, tais como: Espanha, Portugal, Flandres, Nápoles e Milão; além de colônias no além-mar, como aquelas no Novo Mundo. Para uma reflexão deste e outros significados políticos da expressão, ver: Miranda (2016, p. 30-36). 14 Sobre essa reviravolta diplomática no conturbado ano de 1598 e seu impacto na sociedade inglesa, ver: Werham (1994, p. 191-233); MacCaffrey (1992, p. 196-219; 220-221). 
sões acaloradas em Londres, além de uma batalha de textos entre dois partidos rivais: aqueles que eram a favor do estabelecimento da paz, e aqueles que se posicionavam contra. $O$ partido pró-guerra era liderado por Robert Devereux (1566-1601), Conde de Essex, e contava com outras importantes figuras, como a de Henry Wriothesley (1573-1624), Conde de Southampton, a quem Shakespeare dedicou as primeiras publicações de seus poemas. Por sua vez, o partido pró-paz contava com a inclinação da própria rainha. Embora o auge da luta entre esses dois grupos tenha ocorrido em 1598, o processo diplomático se arrastou até Ricardo o início do século seguinte, quando naufragou sem alcançar resultados Cardoso concretos. Shakespeare, nesse momento tenso, parece ter representado in utramque partem a monarquia inimiga da Inglaterra através da dupla Dom Pedro e Dom João em Muito Barulho por Nada.

A fonte que o poeta utilizou para a escrita da peça, a vigésima segunda novela de A Primeira Parte da Novela (c. 1554), de Mateo Bandello (1485-1561), tem como pano de fundo um evento histórico real chamado de Vésperas Sicilianas. Em 1282, Pedro III de Aragão (1239-1285) se aliara aos sicilianos em luta contra a ocupação francesa no sul da Itália pelas tropas de Charles d'Anjou (1226-1285). Pedro III utilizou Messina como sede para suas ações militares e, após a derrota dos franceses, foi coroado como Rei da Sicília. A novela de Bandello começa após a vitória de Dom Pedro e, além deste, apresenta a história principal que servirá de fonte para a trama de Muito Barulho por Nada. O Dom Pedro de Shakespeare, assim, evocaria um herói importante no passado da Monarquia Hispânica, e indiretamente referenciaria as vantagens de tê-la como aliada, algo que agradaria os partidários pela paz em 1598.

Para representar o outro lado da disputa, o dos partidários pelo seguimento da guerra, Shakespeare escolheu evocar como oposto quase simétrico a Dom Pedro outra figura histórica ibérica, Juan de Austria (15471578), meio-irmão de Felipe II, apresentado na peça como Dom João, o irmão bastardo de Dom Pedro. Juan, filho ilegítimo de Carlos V (15001558), tornou-se famoso graças à vitória na Batalha de Lepanto (1571), quando a Espanha o designou para liderar uma frota de aliados cristãos no Mediterrâneo em socorro à República de Veneza na luta contra os turcos. A vitória em Lepanto foi então celebrada em toda a Europa como marco de detenção do avanço turco no ocidente. Assim como Pedro III de Aragão, Juan também escolheu Messina como sede de suas operações militares, a mesma cidade utilizada por Shakespeare para a ação da peça. 
Alguns anos após a vitória no Mediterrâneo, Juan de Austria retirou-se para Flandres onde, segundo Hugh M. Richmond (1979), tramou casar-se com Mary Stuart (1542-1587), atacar a Inglaterra e, junto da escocesa, tornar-se monarca. Segundo Richmond, seria dele a ideia de construir uma Invencível Armada para destituir do trono Elizabeth I, plano levado a cabo em 1588 por seu meio irmão, Felipe II. Portanto, em Muito Barulho por Nada temos a força militar da Monarquia Hispânica representada in utramque partem por meio das referências às Vésperas Sicilianas na composição do digno Dom Pedro, assim como à Batalha de Lepanto no traiçoeiro Dom João. Em comum, a ação em Messina como ponto estratégico, embora trezentos anos separem os dois eventos.

Quentin Skinner (2014) considera que Shakespeare, na apresentação das múltiplas facetas de um problema, concedeu especial atenção a

A ambiguidade como princípio retórico em Shakespeare 99 outros dois elementos retóricos: inventio, invenção criativa dos argumentos; e dispositio, a disposição desses. Em Forensic Shakespeare, o destacado historiador da Escola de Cambridge se debruçou sobre cenas de julgamento forense ou moral em peças escritas entre 1595 e 1604, buscando entender como o poeta apresentava dois lados de uma demanda através de prossecução e defesa perante um juiz. Quanto a este tipo de situação, a boa disposição dos argumentos era vista como fundamental para o convencimento e posterior ganho da causa. Um bom exemplo oferecido por Skinner é a disputa entre Brutus e Marco Antônio no julgamento pela plebe do assassinato de Júlio César na peça homônima (c. 1599). Brutus busca despertar emoções fortes em falas vigorosas, com distribuição homogênea dos argumentos que justificavam a morte de César como medida mais segura para a liberdade dos romanos. Já Marco Antônio, em seu argumento inicial, exime-se de condenar a ação do outro personagem, mas com o avançar do discurso aumenta gradativamente as ironias com que marca o assassinato, reservando para o momento final os sentimentos catárticos que busca despertar nos ouvintes quando levanta a veste do morto e exibe suas feridas. A fictícia audiência mostra-se unânime em condenar a ação de Brutus. Marco Antônio sai vitorioso não apenas por seus argumentos, mas por distribuí-los bem em seu discurso.

Se pensarmos na distributio da composição das falas de Dom Pedro, podemos ver que o dramaturgo parece ter escolhido à risca o único momento na peça em que o personagem mostra seu lado obscuro. Dom Pedro age mal quanto a Hero e seu pai, mesmo hospedado em sua casa, e o faz enganado pelo irmão Dom João. No entanto, essa ocasião em que o príncipe 
de Aragão se comporta de forma ofensiva é a mesma em que a maior parte dos personagens da peça também revela seu pior lado. Quando todos são perdoados ao final, Dom Pedro não pode ser dispensado de receber a mesma condescendência. Assim, vemos que Shakespeare, na distributio das falas que revelam o caráter de Dom Pedro, mesmo que essas não estejam em um discurso linear, parece ter escolhido cuidadosamente o momento em que dimensiona suas ações negativas, dispensando-o de condenação direta, embora aquelas existam e pudessem servir para certo agrado do grupo anti-espanhol em 1598. Contrabalançando in utramque partem e dispondo falas

Ricardo

Cardoso para a representação positiva e negativa da Monarquia Hispânica na peça, por meio de Dom Pedro e de Dom João, o dramaturgo evitaria ofender os dois partidos em disputa em torno da negociação pela paz com a Espanha e, assim também, alguma represália por parte de algum deles ${ }^{15}$.

Alguns indícios apontam para situação parecida em Otelo. Em 1603, poucos anos após o fracasso daquela primeira tentativa de negociação entre as duas Coroas, a velha rainha morreu e James VI da Escócia (1566-1625) ascendeu ao trono inglês como James I. Uma das primeiras medidas do novo Rei foi o anúncio de cessar-fogo contra a Espanha, deixando clara sua intenção de estabelecer a paz. Em agosto de 1604, o fim do conflito foi oficialmente declarado com a assinatura do Tratado de Londres. Shakespeare e sua companhia no ano anterior haviam recebido patronagem do novo monarca, tornando-se os Homens do Rei, e em uma de suas primeiras missões na nova condição entretiveram por dezoito dias a delegação espanhola presente em Somerset House para as festividades pelo fim da guerra. Entretanto, a paz não foi recebida pelos londrinos da mesma forma que pela Coroa.

A Guerra Anglo-Espanhola decorrera de diferentes motivos, econômicos e diplomáticos, no entanto, o mais utilizado pela propaganda elisabetana para justificá-la era o religioso. Os súditos protestantes de Elizabeth I viam a Espanha como uma ameaçadora nação de hereges, subservientes ao Papado, visto como a besta apocalíptica descrita no Livro

15 Muitos colegas dramaturgos de Shakespeare foram presos por não terem o mesmo cuidado em referências explícitas à política interna ou externa em suas peças, dentre eles Ben Jonson (1572-1637), encarcerado por satirizar escoceses em Eastward Ho (1604-5), peça escrita no mesmo contexto de mudança de dinastia que Otelo (FRASER, 2000, p. 121-2). 
das Revelações ${ }^{16}$. Por outro lado, os católicos ingleses viam na Espanha a possibilidade de socorro à perseguição que viviam por seus conterrâneos. Quando James I ascendeu ao trono e deu claros sinais de uma política religiosamente mais tolerante e pró-espanhola, o jogo parece ter virado, os protestantes passaram então a se sentir ameaçados, enquanto os católicos viram-se na perspectiva de voltarem à prática da velha fé sem desassossegos. Para os defensores da reformada Igreja da Inglaterra, a Espanha deixara de ser um oponente externo e passara a ser vista como um inimigo agora interno, pois que seria aliada do monarca em seu novo reinado, e dos papistas ingleses ${ }^{17}$. Neste contexto, a paz foi recebida friamente pelos londrinos, em sua maioria protestantes, criticada nos púlpitos das igrejas e lamentada por aqueles que desejavam continuar a guerra ${ }^{18}$. Nesse clima de desconfiança de uns e esperança de outros, ocasionadas

A ambiguidade como princípio retórico em Shakespeare pela nova aliança diplomática, Otelo foi encenada alguns meses depois na temporada de fim de ano da Corte em 1604, com a possível presença do novo embaixador espanhol na audiência.

Segundo a crítica Barbara Everett em artigo publicado na Shakespeare Survey em 1982, e estudiosos posteriores, Shakespeare compôs os personagens de Otelo e Iago com intencional ressonância espanhola ${ }^{19}$. Para agradar o novo patrono, o dramaturgo utilizou como pano de fundo dramático a referida Batalha de Lepanto, aquela em que Juan de Austria derrotou os turcos no Mediterrâneo, tema utilizado por James I em um poema que escreveu durante a mocidade e que foi publicado em Londres em 1603 como His Maiesties Lepanto, or Heroicall Song Being Part of His Poeticall Exercises at Vacant Houres. Em Otelo, o protagonista traria consigo reminiscências dos mouriscos espanhóis, mercenários que supostamente teriam integrado a armada de Juan de Austria. Já Iago tem como nome o do santo mais popular na Espanha, Saint Iago, a quem dirigiam orações os fiéis que se lançavam na luta contra os mouros durante a Reconquista Espanhola. Seus devotos o chamavam de 'o mata-mouros'.

Em estudo de Medida por Medida (c. 1603-4), o historiador Conal Condren (2009) sugere que o dramático uso do in utramque partem por Shakespeare transpunha as formas costumeiras de diálogo ou alterca-

\footnotetext{
16 O dramaturgo Thomas Dekker dramatizou bem essa visão do papado e da Espanha pelos ingleses na peça A Prostituta da Babilônia (1606).

17 "Papista" era uma expressão utilizada pelos protestantes ingleses para se referirem aos católicos.

18 Para a desconfiança que marcou o acolhimento da paz, ver: Honan (2001, p. 372); Griffin (2009, p. 171-173). 19 Os críticos mais destacados que seguiram a proposta de Everett sobre a ressonância espanhola em Otelo são: Griffin (2009, pp. 168-206); e mais recentemente Andrew Hadfield (2017, p. 286-309).
} 
Ricardo

Cardoso

ção de discursos. O dramaturgo utilizava personagens diferentes em momentos diversos para apresentar o mesmo lado de uma questão, às vezes sobrepunha outras àquela principal, o que resultava em efeito vertiginoso. A historiadora Cathy Curtis (2009, p. 61-2) parece referir-se em parte a esse fenômeno quando chama a criação do poeta de dramaturgia interativa, construída por diferentes pontos de vista sobre um assunto e até mesmo através de ações contraditórias de um único personagem em diferentes momentos da trama. Curtis (2009, p. 68-70) usa como exemplo o caso de Próspero, protagonista de A Tempestade (c. 1611), para tratar de um tema em ebulição na época: da melhor formação de um governante. No debate estavam em oposição a ideia de vida ativa, calcada na experiência prática para a construção do bem comum, e a de vida contemplativa, dedicada aos estudos e afastada da sociedade. Próspero apresenta em sua gênese anterior e no momento em que o vimos em cena esses dois elementos opostos da matéria. Como duque de Milão, perdeu o trono por envolver-se com livros na vida contemplati$v a$, fase vista por muitos como necessária à formação humanista de um governante justo. No entanto, em sua vida ativa como soberano da ilha, transparece a ideia de que esses estudos não lhe serviram de preparação, tampouco o próprio exercício do governo, pois mesmo após anos ali exilado mostra-se tirano com Caliban e Ariel, a quem escravizou.

Ao pensarmos que a argumentação de um tema in utramque partem pode ser sobreposta por outros, também discutidos pela abordagem de pontos de vista antagônicos, como sugere Condren, e ainda através de um mesmo personagem, como mostra Curtis, são desvelados novos ângulos no retrato da Espanha feito por Shakespeare em Otelo ${ }^{20} .0$ protagonista, como pretensa representação heroica do antigo inimigo, trai esse intento na própria composição de seu nome. Graças ao domínio árabe na Península Ibérica, espanhóis, judeus, mouros e turcos mesclavam-se no imaginário inglês na passagem do século XVI para o XVII. Esta sobreposição era parte constituinte da formação da chamada Lenda Negra, propaganda anti-espanhola que se espraiava pela Inglaterra

20 A crítica Emily Pitts Donahoe (2018) escreveu um artigo interessante em que defende o in utranque partem como questão central em Otelo. A peça, preferida por estudiosos de retórica renascentista por tratar de persuasão, seria em si uma reflexão sobre o lado positivo e o negativo da abordagem in utranque partem de um tópico. Segundo Donahoe, o dispositivo ofereceria a possibilidade de manipulação, aspecto negativo representado em Iago. Por outro lado, o conhecimento e exercício dessa técnica evitaria justamente a manipulação por outro agente, algo que se fosse praticado por Otelo, o impediria de cair na armadilha montada retoricamente por Iago. 
naquele exato momento ${ }^{21}$. O nome Otelo referenciaria por semelhança sonora o Império Otomano. Essa associação ganharia ainda maior ênfase quando o protagonista ao fim da peça compara seu fim trágico ao de um turco em Alepo, ambos mortos pelas mãos do mesmo agente, o próprio Otelo. Assim, o personagem evocaria tanto os turcos quanto os espanhóis que se enfrentaram na Batalha de Lepanto, ambos os povos vistos como heréticos perigosos pelos reformados ingleses. O personagem representaria sozinho dois lados de uma questão, mas não em diferentes momentos da trama, como o protagonista de A Tempestade, e sim na contradição entre seu nome, que remete aos otomanos, e a ação que empreende, derrotá-los. 0 único momento em que esses dois aspectos convergem é o de sua morte. Para tornar ainda mais complexa a composição, o protagonista, como representação do heroico passado espanhol

A ambiguidade como princípio retórico em Shakespeare

Para concluir, podemos avaliar a possibilidade de que os momentos em que foram escritas as duas peças aqui tratadas tenham sido determinantes para a escolha de Shakespeare em representar ambiguamente a Monarquia Hispânica. Os anos de 1598 e 1604 foram marcados pela discussão entre aqueles que apoiavam o estabelecimento da paz e os que desejavam a continuidade da guerra. Com o cuidado que a situação exigia, pois ambas as discussões foram acaloradas e abrangeram tanto a audiência dos teatros públicos quanto a Corte e Coroa, o poeta parece ter recorrido à apresentação de "duas Espanhas", cada uma destinada, ao menos num primeiro lance de vista, a agradar um dos grupos envolvidos no embate. Através do recurso retórico do in utramque partem, e atenção à dispositio dos argumentos, Shakespeare representou o costumeiro inimigo de duas formas antagônicas, como se estivesse mostrando ganhos e perdas na reaproximação diplomática com ele. Dom Pedro e Otelo surgem em cena como militares vitoriosos nas guerras em que participam, representam uma Espanha vigorosa em suas campa-

21 Sobre o assunto, ver: Griffin (2009) e Vitkus (1999). 
nhas, boa para se ter como aliada na paz justamente por ser ameaçadora enquanto inimiga. Já Dom João e Iago evidenciam o aspecto traiçoeiro que caracterizava o velho oponente no imaginário inglês, aquele que trai tratos e em quem não se poderia confiar. Com essa medida cautelar de apresentação em cena de "duas Espanhas", cada uma com suas próprias contradições e idiossincrasias, Shakespeare evitaria ofender qualquer um dos dois partidos que se enfrentavam em relação ao fim do conflito, tanto em 1598 quanto em 1604, cujos membros estariam presentes durante a performance.

Ricardo Como não temos registros do contrário, nesses contextos a ambiguiCardoso dade pode ter salvo o dramaturgo de riscos ou represálias. Se nessa época os católicos ingleses utilizavam a equivocação teorizada por Southwell e Garnet para se salvarem de perseguições religiosas, o poeta poderia fazer algo semelhante em suas peças quando também precisasse tomar certa precaução para escapar de retaliações em momentos políticos tumultuados, utilizando dispositivos como a abordagem in utramque partem de um problema e cuidado com a disposição dos argumentos. Neste sentido, independentemente da origem confessional ou não da habilidade de Shakespeare para a evasão, podemos dizer com alguma segurança que alguns artifícios que ele utilizava em seus textos para causar certa ambivalência no tratamento de tópicos polêmicos eram emprestados da retórica.

Ricardo Cardoso, Stratford-upon-Avon, setembro de 2019.

\section{REFERÊNCIAS}

ALTMAN, Joel B. The Tudor Play of Mind. Rhetorical Inquiry and the Development of Elizabethan Drama. Berkeley; Los Angeles: University of California Press, 1978.

,Joel B. The Improbability of Othello. Rhetorical anthropology and Shakespearean selfhood. Chicago: The University of Chicago Press, 2010.

ARISTÓTELES. Obras Completas de Aristóteles. Retórica. António Pedro Mesquita (coordenação). Prefácio e introdução de Manuel Alexandre Júnior. Tradução e notas de Manuel Alexandre Júnior, Paulo Farmhouse Alberto e Abel do Nascimento Pena. São Paulo: Martins Fontes, 2012. 
ARMITAGE, David (ed). British Political Thought in History, Literature and Theory. 1500-1800. Cambridge: Cambridge University Press, 2006.

Shakespeare's properties. In.: ARMITAGE, David; CONDREN, Conal; FITZMAURICE, Fitzmaurice (ed's). Shakespeare and Early Modern Political Thought. Cambridge: Cambridge University Press, 2009, p. 25-45. ; CONDREN, Conal; FITZMAURICE, Fitzmaurice (ed's). Shakespeare and Early Modern Political Thought. Cambridge: Cambridge University Press, 2009.

BANDello, Matteo. La Prima Parte de Le Novelle Del Bandello. A ambiguidade como princípio retórico em Shakespeare Lucca: Il Busdrago, 1554.

CARDOSO, Ricardo. Guerra Anglo-Espanhola (1588-1604) na Obra Dramática de Shakespeare: o palco entre tempestade. In.: CLOSEL, Régis Augustus Bars; MARIN, Ronaldo (Orgs.). Shakespeare. 450 Anos. BMA Edições. São Paulo, Instituto Shakespeare Brasil - Cena IV Shakespeare Cia, 2014, p. 107-127.

A Invencível Armada na Pena de Shakespeare: diplomacia e dramaturgia na transição do século XVI para o XVII. 216f. Dissertação (Mestrado em História Social). Faculdade de Filosofia, Letras e Ciências Humanas, Universidade de São Paulo. São Paulo-SP, 2016. Disponível em: <http://www.teses.usp.br/teses/disponiveis/8/8138/tde09122016-141257/pt-br.php> ${ }_{2}$ Acesso em: 16 de junho de 2019.

CONDREN, Conal. Unfolding the 'properties of government': the case of Measure for Measure and the history of political thought. In.: ARMITAGE, David; CONDREN, Conal; FITZMAURICE, Fitzmaurice (ed's). Shakespeare and Early Modern Political Thought. Cambridge: Cambridge University Press, 2009, p. 157-175.

CURTIS, Cathy. The active and contemplative lives in Shakespeare's plays. In.: ARMITAGE, David; CONDREN, Conal; FITZMAURICE, Fitzmaurice (ed's). Shakespeare and Early Modern Political Thought. Cambridge: Cambridge University Press, 2009, p. 44-63. 
DONAHOE, Emily Pitts. In Utramque Partem: Arguing Both Sides of the Question in Othello. In.: English Literary Renaissance, Chicago, volume 48, n. 3, Autumn 2018, p. 314-338.

EVERETT, Barbara. Spanish Othello: the making of Shakespeare's moor. In.: Shakespeare Survey, Cambridge, nº 35, p. 101-112, 1982.

FRASER, Antonia. A Conspiração da Pólvora. Terror e fé na Revolução Inglesa. Tradução de Alda Porto. Rio de Janeiro: Record, 2000.

Ricardo

Cardoso

GAJDA, Alexandra. Debating War and Peace in Late Elizabethan England. In.: The Historical Journal, Cambridge, Volume 52, Issue 106 04, p. 851-878, December 2009.

GARNET, Henry. Treatise of Equivocation. Edited by David Jardine. London: Longman, Brown, Green and Longmans, 1851.

GREENBLATT, Stephen. O Novo Historicismo: ressonância e encantamento. In.: Estudos Históricos, Rio de Janeiro/RJ, v. 4, n. 8, p. 244-261, 1991.

Como Shakespeare se tornou Shakespeare. Tradução de Donaldson M. Garshagen; Renata Guerra. São Paulo: Companhia das Letras, [2004] 2012.

GRIFFIN, Eric J. English Renaissance Drama and the Specter of Spain. Ethnopoetics and Empire. Philadelphia: University of Pennsylvania Press, 2009.

HADFIELD, Andrew. Lying in Early Modern English Culture. From the Oath of Supremacy to the Oath of Allegiance. Oxford: Oxford University Press, 2017.

HAUSER, Arnold. Maneirismo. A crise da renascença e o surgimento da arte moderna. Tradução de J. Guinsburg e Magda França. São Paulo: Perspectiva, [1965] 2007.

HONAN, Park. Shakespeare. Uma vida. Tradução de Sonia Moreira. São Paulo: Companhia das Letras, 2001. 
HOWARD, Jean E. Dramatic Traditions and Shakespeare's Political Thought. In.: ARMITAGE, David (ed). British Political Thought in History, Literature and Theory. 1500-1800. Edited by David Armitage. Cambridge: Cambridge University Press, 2006, pp. 128-144.

JAMES VI and I. His Maiesties Lepanto, or Heroicall Song Being Part of His Poeticall Exercises at Vacant Houres. London: Simon Stafford and Henry Hooke, 1603.

A ambiguidade como princípio

JONES, Emrys. 'Othello', 'Lepanto' and the Cyprus Wars. In.: Shakespeare Survey, Cambridge, no 21, p. 47-52, 1969.

retórico em

Shakespeare

MAcCAFFREY, Wallace T. Elizabeth I. War and Politics, 1588-1603.

Princeton: Princeton University Press, 1992.

MIRANDA, Marcella. Aspectos Práticos de uma teoria absoluta. A monarquia e as Cortes na Espanha de Felipe II, 1556-1598. Belo Horizonte: Fino Traço, 2016.

RICHMOND, Hugh. M. Much Ado About Notables. In.: Shakespeare Studies, n. XII, p. 49-63, 1979.

SCATOLIN, Adriano. A Invenção no Do Orador de Cícero. Um estudo sob a luz de Ad Familiares I, 9, 23. 308f. Tese (Doutorado em Letras Clássicas). Faculdade de Filosofia, Letras e Ciências Humanas, Universidade de São Paulo. São Paulo-SP, 2009.

SCHWARTZ, Stuart B. Cada Um na Sua Lei. Tolerância religiosa e salvação no mundo atlântico ibérico. São Paulo: Companhia das Letras, 2009.

SHAKESPEARE, William. The New Oxford Shakespeare. The complete works; critical reference edition. General editors Gary Taylor, John Jowett, Terri Bourus, Gabriel Egan. Oxford: Oxford University Press, 2017.

SHAKESPEARE, William. Much Ado About Nothing. Edited by Claire McEachern. London: Bloomsbury, 2014. 
SHAKESPEARE, William. Othello. Revised Edition. Edited by E. A. J. Honigmann with a new introduction by Ayanna Thompson. London: Bloomsbury Arden Shakespeare, 2016.

SKINNER, Quentin. Shakespeare and the Humanist Culture. In.: Shakespeare and Early Modern Political Thought. Cambridge: Cambridge University Press, 2009, p. 271-281.

Ricardo Quentin. Forensic Shakespeare. Oxford: Oxford University Cardoso

SIMPSON, J. A.; WEINER, E. S. C. The Oxford English Dictionary. 20 volumes. Prepared by J. A. Simpson and E. S. C. Weiner. Oxford: Clarendon Press, 1989

TAYLOR, Gary. The Canon and the Chronology of Shakespeare's plays. In: WELLS, S.; TAYLOR, G.; JOWETT, J.; MONTGMOMERY, W. William Shakespeare. A Textual Companion. Oxford, Oxford University Press, 1997, p. 69-144.

VITKUS, Daniel J. Early Modern Orientalism: Representations of Islam in Sixteenth-and Seventeenth-Century Europe. In.: BLANKS, David R.; FRASSETTO, Michael (Ed's). Western Views of Islam in Medieval and Early Modern Europe. Perception of Other. New York: St. Martin's Press, 1999, pp. 207-230.

WERNHAM, R.B. The Return of the Armadas. The last years of the Elizabethan war against Spain, 1595-1603. Oxford: Clarendon, 1994.

WIGGINS, Martin; RICHARDSON, Catherine. British Drama, 15331642. A catalogue. 11 vol. Oxford: Oxford University Press, 2007-atual. 